\title{
Spectral features of geomagnetic low point displacement and its mechanism*
}

\author{
ZHANG Xue-min ${ }^{1), *}$ (张学民) QIAN Jia-dong ${ }^{1}$ (钱家栋) WANG Ya-li ${ }^{2}$ (王亚丽)

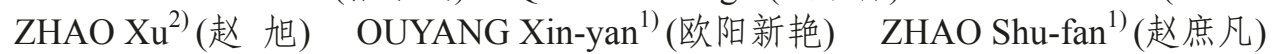 \\ 1) Institute of Earthquake Science, China Earthquake Administration, Beijing 100036, China \\ 2) China Earthquake Networks Center, China Earthquake Administration, Beijing 100045, China
}

\begin{abstract}
In this paper, Changli station in Hebei Province was taken as an example, in which the minute data of geomagnetic $Z$ component was used to analyze the spectral values of its main frequencies during normal time, geomagnetic storm time and low point displacement time interval respectively. After fitting of ten high spectral values to logarithmic functions, it is found that, by using same length of data, the spectral values at geomagnetic storm time increase apparently compared with those at normal time, especially at the high frequency segment. While low point displacement occurred, the spectral values at high frequency are approximate to those at normal time, but at period above 4 hours they are mostly lower than those at normal time. Comparison of accumulating of some FFT results at low point displacement and normal time shows that, spectral values at periods of 8.5 and 13.7 hours increase at low point displacement time relative to those at normal time. Compared with the images of $N_{\mathrm{e}}$ observed at DEMETER satellite, it is illustrated that the occurrence of geomagnetic low point displacement is well corresponding with the increase of $N_{\mathrm{e}}$ in ionosphere. Finally it was discussed about those spectral features and the occurrence mechanism of geomagnetic low point displacement.
\end{abstract}

Key words: geomagnetic $Z$ component; low point displacement; FFT; DEMETER; electron density CLC number: P318. $2^{+} 4$ Document code: A

\section{Introduction}

The study with geomagnetic methods to predict earthquakes in China has been developed for a long time. There are kinds of techniques, such as geomagnetic loading/unloading response ratio method (SHI et al, 2002), geomagnetic transfer function (LI, 2005), low point displacement (DING and HUANG, 1988) and so on, in which low point displacement method has been widely employed in routine prediction work and obtained better effect. XIE and QIAO (2003) and DING et al (2006) used more than two dividing lines of low point displacement to do research on the relationship between them and earthquakes to reduce the predicted scale. GUO et al (1977) thought that around the time of multiplying 9 after geomagnetic storms, the earthquakes are more easily occurred. WU (2004) researched in detail on the phenomena of low point displacement in Sichuan Province, and combined the methods of "geomagnetic low point displacement" and

\footnotetext{
* Received 2007-12-13; accepted in revised form 2008-07-08.

Foundation item: National Science and Technology Program (2006BAC011302-04-02) and Basic Research Project in Institute of Earthquake Science, China Earthquake Administration.

^Author for correspondence: zhangxm96@126.com
} 
"geomagnetic storm" to predict the earthquake occurring time (WU et al, 2003). HUANG and YU (2000) studied the relationship between anomalous characteristics of low point displacement and seismicity. LI and LIANG (1989) pointed that the low point displacement method based on multi-stations produced different effect in different regions; as for the southwestern area, it was bad, but being effective in North China.

At the same time, the ionospheric anomalous phenomenon has attracted more attention. Analyzing the magnetic field, ionospheric anomalies and their features prior to the Mani 7.5 earthquake on November 8, 1997 and the Kunlunshan Pass West 8.1 earthquake on November 14, 2001, DING et al $(2004,2005)$ found well consistence in short and imminent temporal and spatial distribution features between magnetic field and ionosphere. Around the epicentral area, there occurred anomalies of geomagnetic diurnal variation, foF2 (critical frequency of F2 layer in ionsphere) presenting obvious anomaly at the Lhasa station, while low point displacement appeared one month before the earthquake with the dividing line passing the epicentral area. Since the observation of DEMETER satellite from June, 2004, a M5.5 earthquake occurred at west coast of Honshu, Japan on August 20, 2004 and a M8.5 earthquake occurred at Sumatra, Indonesia on March 28, 2005. Prior to these two earthquakes, the plasma parameters (including electron density, electron temperature and ion density, ion temperature) showed anomalous variation (Parrot et al, 2006). Pulinets et al (2000) studied the events at high latitude (Alaska), middle latitude (central Italy) and lower latitude (New Zealand), and the results illustrated that weak ionospheric disturbances were presented in a few days before the main earthquakes, while the disturbed areas were not just above the epicentral areas, but deviating a little. With the coming of the earthquakes, disturbed areas became larger and the anomalous amplitude increased. Some hours later after the events, disturbances recovered gradually. Under some conditions, disturbances not only occurred near the epicentral areas, but may propagate to the conjugate points along the magnetic lines (Pulinets et al, 2000).

Many seismologists have studied the occurrence mechanism of geomagnetic low point displacement. Based on the data of geomagnetic vertical component at Jiayuguan station in the period of 1993 1998, ZHAO et al (2005) suggested that convection of deep seated media could cause the variation of underground conductivity and magnetic susceptibility, leading to the variation of geomagnetic field. At the same time, the movement of underground media with high temperature also accompanies the anomalies of geothermal heat flow. When this relative vertical movement of mantle media is overlapped on the crust, it may result in crustal tectonic transformation and produce aseismic anomaly of geomagnetic low point displacement.

Electromagnetic field is an effective carrier connecting the space and the Earth. More attention has been put on its application to earthquake prediction. Geomagnetic low point displacement is an objective phenomenon. Whether is there any relationship between its occurrence and space ionospheric disturbances or the variation of underground media electricity? On the basis of analysis to every example of low point displacement, the anomalous variation features of magnetic spectrum during the time of low point displacement is studied, and compared with the ionospheric data observed by satellite, its occurrence mechanism has been discussed in this paper.

\section{Basic information of the station and data processing method}

The Changli station, located at eastern Hebei Province, China, is one of the earliest stations built in China, belonging to national network of geomagnetic observation stations. It has continu- 
ously observed the geomagnetic field for more than 30 years. Since 2000, the digital geomagnetic observation with minute sampling replaces the earlier analogue records after station transformation, which assure observing precision and the amount of data compared with original hourly values.

Because the low point displacement occurs in a few hours, and does not continue for a few days, its duration is not long. In order to analyze its spectral features, spectrum amplitude values at single frequency was calculated by Fast Fournier Transformation, using geomagnetic minute data of $Z$ component in a 3-days interval (LU et al, 2000), then prominent periods in the spectral values were analyzed and discussed.

\section{Distribution features of short-period geomagnetic spectrum}

The most obvious disturbance in geomagnetic observation is the magnetic storms. To reflect the spectral variation of magnetic field activity at different time, the spectrum during magnetic storms were compared with that of normal time. From November 8 to 10, solar activity was strong, and strong magnetic storms were recorded at surface magnetic field observation, with the biggest $K$ index being 9. This geomagnetic activity lasted a longer time, continuing for whole 3 days. Figure 1 present the geomagnetic $Z$ component minute data at Changli station and hourly data of geomagnetic Dst index during these three days, in which the Dst index data was downloaded from international geomagnetic website. It can be seen that, the Dst index decreased to -300 on November 8 , illustrating fierce magnetic storm activity. While two magnetic storms were recorded respectively on January 21 and May 15, 2005, their duration and intensity were much smaller than that on November 8, 2004. Figure 1 shows that high frequency signals were exhibited obviously
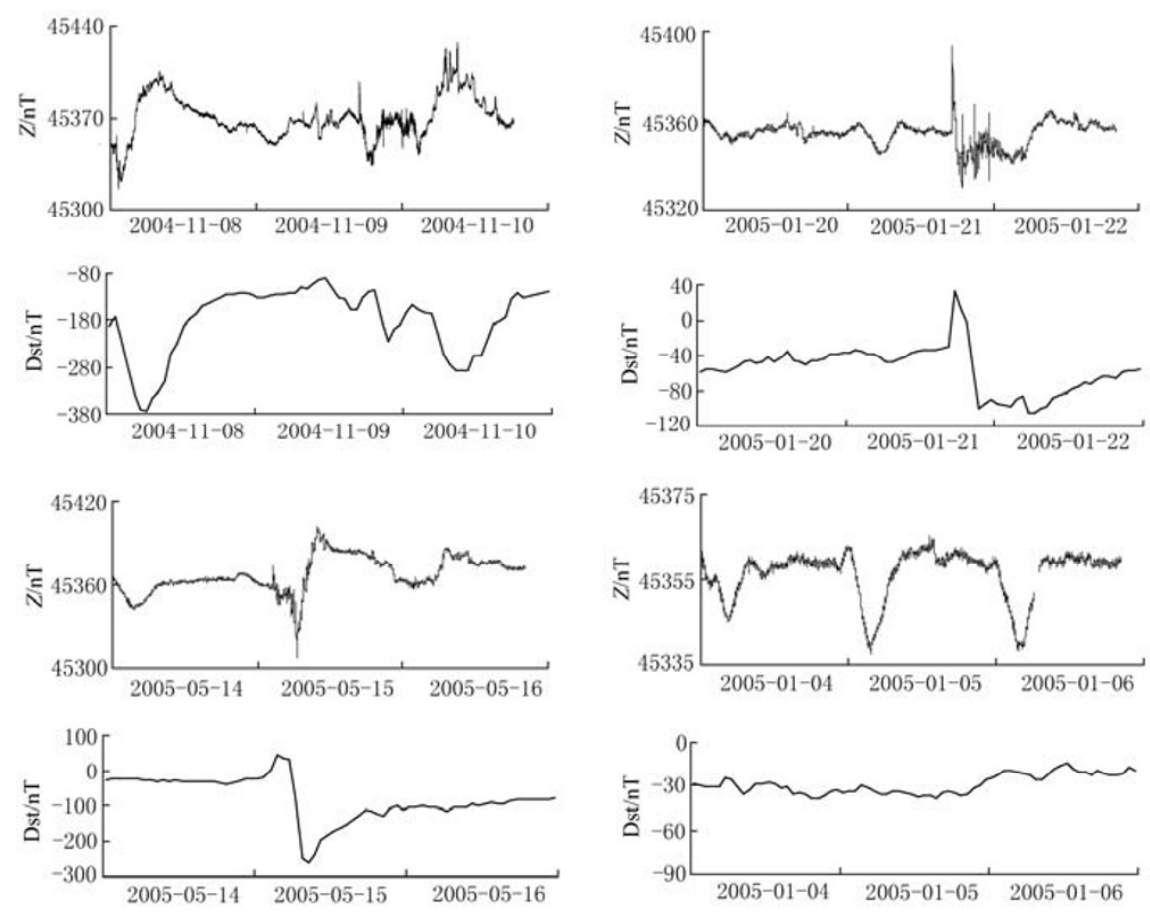

Figure 1 Curves of geomagnetic $Z$ component and Dst during three geomagnetic storms and a normal period on Changli station (the Universal Time, follows same) 
during magnetic storms and daily variation shapes were apparently changed. Figure 1 also presents one data curve during normal time, which reflects that its daily variation is very regular, typically different from those during magnetic storms.

By FFT, power spectrums were calculated during magnetic storm time and normal time, and the biggest 10 spectral values were selected. The results were shown in Figure 2. In order to reflect the wholly characteristics at different time intervals, curve fitting was done respectively. Seen from original curves and fitted curves, the power spectrums at many frequency points during geomagnetic storm time (solid lines) are higher than those during normal time (dashed lines), with the logarithm spectrum energy higher about an order of magnitude. The fitting curve during the geomagnetic storm on January 21, 2005 crossed at long-period part with that during normal time, which may be related to length of geomagnetic storm duration and energy intensity. Compared with other two geomagnetic storms, the geomagnetic storm on January 21, 2005 is weaker whatever the duration or intensity. The geomagnetic storm on November 2004 lasted the longest time, the daily curves disturbed in these three days and the lowest Dst reached $-373 \mathrm{nT}$. Although the geomagnetic storm on May 2005 lasted a shorter time, the Dst reduced to $-273 \mathrm{nT}$, stronger than that on January 21, 2005.
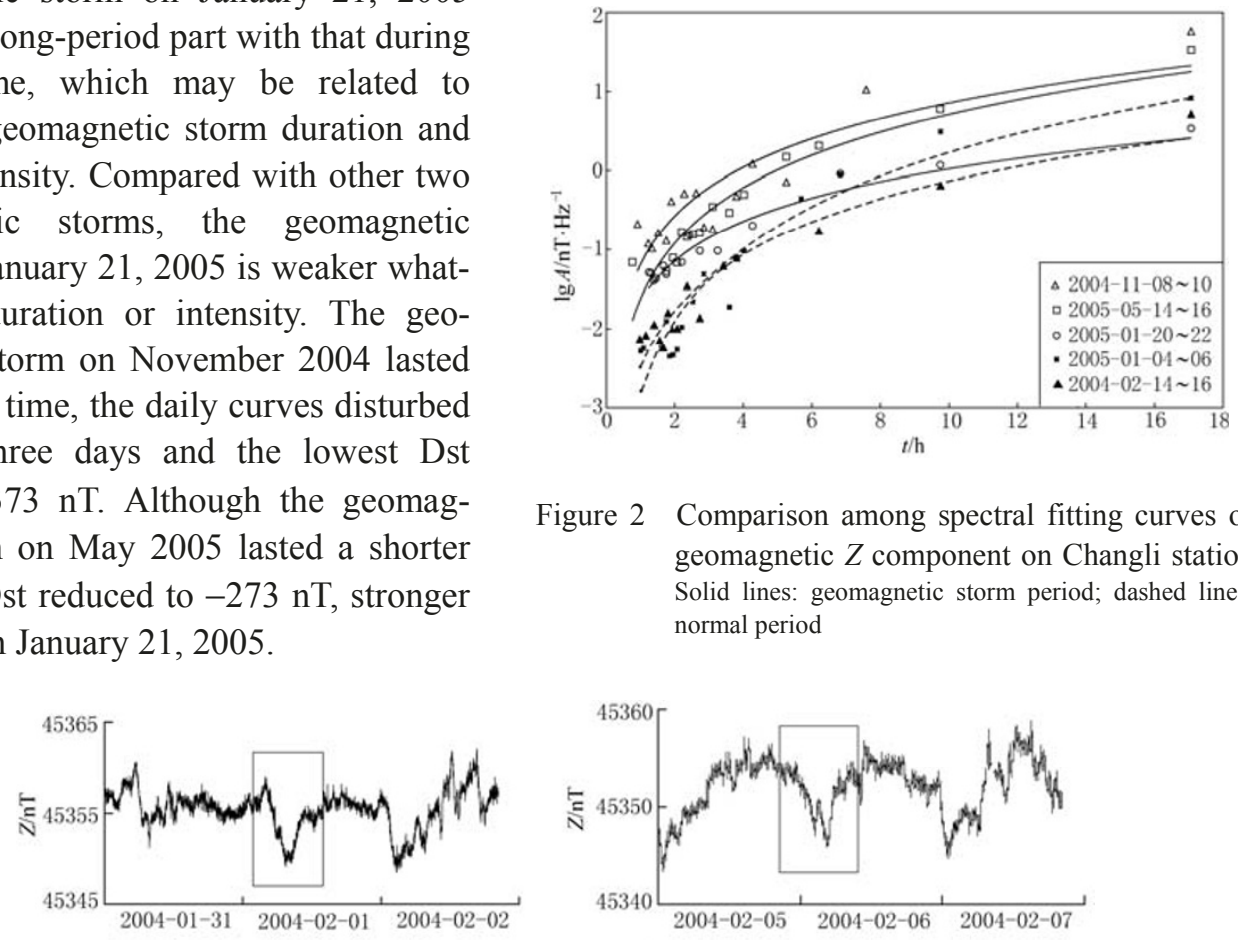

Figure 2 Comparison among spectral fitting curves of geomagnetic $Z$ component on Changli station Solid lines: geomagnetic storm period; dashed lines: normal period
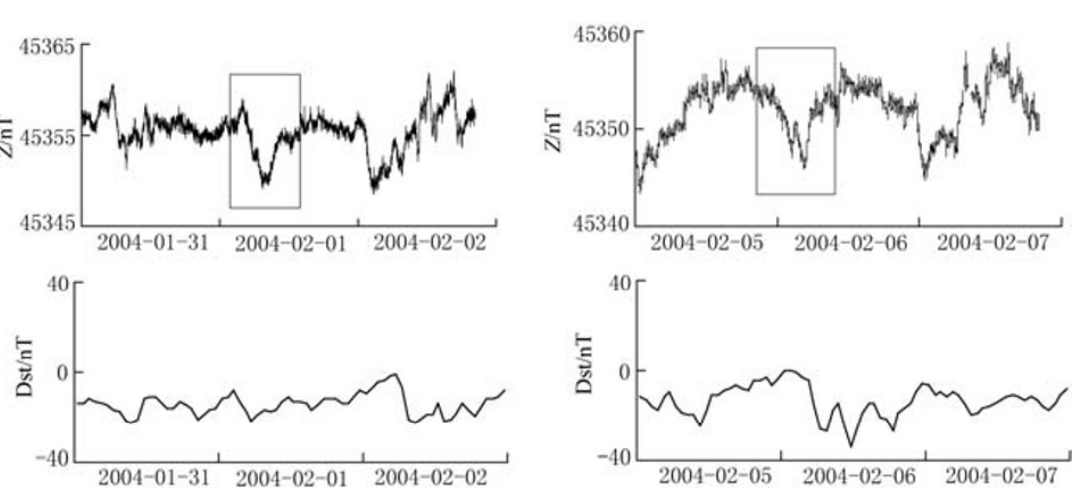

Figure 3 Minute original curves (upper) of geomagnetic $Z$ component and hourly curves (lower) of geomagnetic index Dst during low point displacement periods on Changli station

Low point displacement line was exhibited crossing central China respectively on February 1 and 6, 2004, dividing China into two parts. The Changli station is located at the north part, forming the phenomenon of low point time moving backwards (Figure 3). Based on the Dst record, it was not lower than $-50 \mathrm{nT}$ in three days around the events, with no magnetic storm shown, belonging to quiet geomagnetic time interval. As the same, power spectrum values of each frequency were calculated using 3-days data around these two low point displacement. Ten biggest spectral 


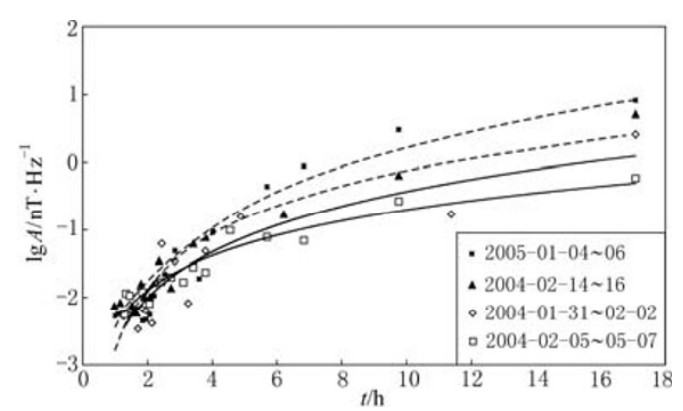

Figure 4 Comparison of spectral fitting curves during low point displacement and normal periods

Dashed lines: normal period; solid lines: low point displacement period values plotted in Figure 4 (blank labels, fitting lines are solid line), the results show that, the spectral energy of periods during low point displacement interval can not be basically distinguished with those during normal time. But with the increase of period, spectral energy decreases gradually, lower apparently than that in normal time.

From the analysis above, it is demonstrated that, the periodical power spectrums during geomagnetic storm interval or low point displacement interval, are both different from that in normal time, being higher during geomagnetic storms especially at the high frequency segment, while the overall

energy is reducing and presenting some difference at long period segment during low point displacement, which all can be differentiated with normal variation.

\section{Main spectrum characteristicsduring low point displacement and its response in space}

In order to reflect the whole spectrum characteristics during low point displacement, 3-days data including the days before and after the low point displacement was selected, 4096 minute values used, then the spectrum values of each frequency were obtained by FFT. During 2002 to 2006, there are 16 events where low point displacement formed and low point time at the Changli station exceeded 2 hours than normal time. Due to the geomagnetic storms occurring during some events, their whole spectrum energy was affected, so they were deleted. Finally 10 low point displacement events at Changli station left, their FFT results at each frequency were cumulated and averaged. While, 3-days FFT results of 12 quiet and normal intervals were added together and averaged, the averaged spectrum is shown in Figure 5. It is seen, consistent with former analysis; the averaged spectrum values at some larger amplitude of normal time are generally higher than those during low point displacement. To give prominence to the variation of high frequency segment, the energy spectrum values were transformed to logarithm as shown in Figure 6. The results show that, many high spectrum values occur from 0.05 (equals to 20 minutes) to 0.5 (equals to 2 minutes) regularly, while no obvious spectrum in normal time. Due to the equidistant distribution of spectrum, it is considered as artificial disturbances. Compared with original observing data, it is found that there exist many impulses with the period of $2 \sim 7$ minute every hour. Because resistivity and magnetic field

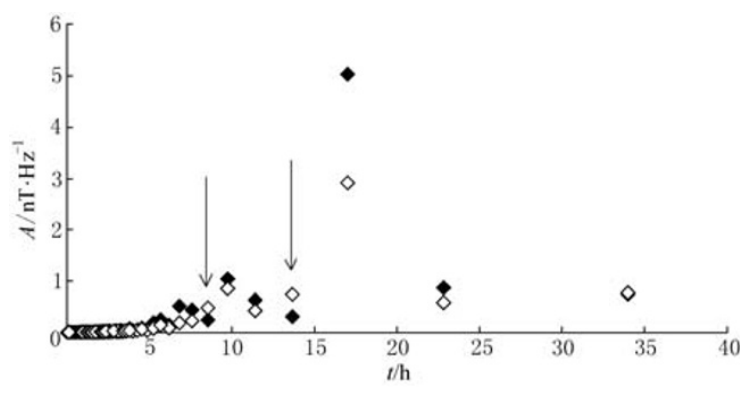

Figure 5 Averaged spectrum during normal and low point displacement periods Solid square: normal period; open square: low point displacement period 
are observed at this same station, routine resistivity observation needs to emit electricity every hour to underground, which may result in the above phenomenon. The FFT analysis results illustrate apparently the spectral feature of a group of disturbances, so it is suggested that this kind of impulse signals should be omitted effectively at the segment of data preprocess.

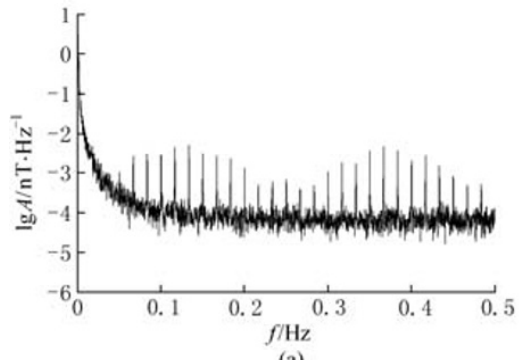

(a)
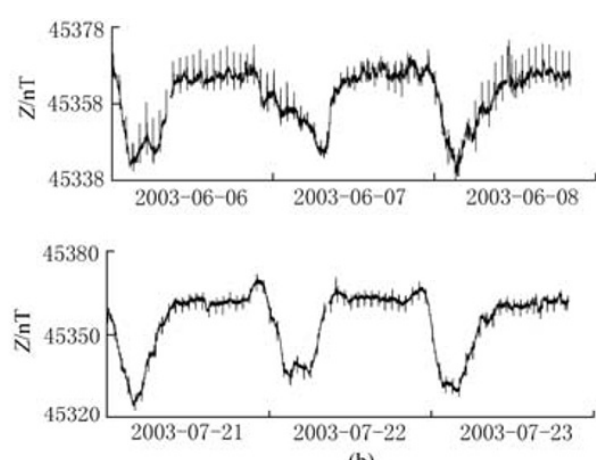

(b)

Figure 6 FFT logarithm spectrum (a) and original disturbed curves (b)

Summing up the characteristics at high and low frequencies, no obvious spectrum were formed during low point displacement occurrence, however whole spectrum decreased. By analysis on the results of Figure 5, only two spectrums in 10 values are higher than that in normal interval, that is the period of 8.5 hour and 13.7 hour (arrows shown in Figure 5). According to the formula of sounding depth by electromagnetic wave $D=\frac{1}{\sqrt{\pi \mu \sigma f}}=\frac{1}{2 \pi} \sqrt{10 \rho T}$, supposing that the resistivity of crust and lithosphere is $1000 \Omega \cdot \mathrm{m}$, the sounding depth of these two periods can reach about $400 \mathrm{~km}$, to mantle asthenosphere. It reflects that during low point displacement occurrence, electromagnetic wave produces disturbances in mantle asthenosphere, illustrating that low point displacement is a deep seated effect to mantle asthenosphere, not a tectonic action in lithosphere and crust, so the source of low point displacement may be related to upwelling of thermal media in deep mantle. Of course, the occurrence of low point displacement is a large regional anomaly, not limited to a small area, whether it is related to the horizontal movement of deep thermal media needs more information accumulation and further study.

Satellite observation provides a lot of spatial electromagnetic data, and it is convenient for analysis on the electromagnetic response among lithosphere and atmosphere, iononsphere. Low point displacement is a kind of regional event, with the scale of more than a few million kilometers. Can such an anomaly results in the disturbance in ionosphere? Or does the local disturbance in ionosphere leads to the movement of geomagnetic low point time? All these are problems drawing attention to electromagnetic researchers. Here, taking 2 low point displacement events as example, electron density $\left(N_{\mathrm{e}}\right)$ data in related time interval on the DEMETER satellite (Parrot et al, 2006; Lebreton et al, 2006) were downloaded, and spatial $N_{\mathrm{e}}$ variation features in these anomalous intervals were analyzed.

On January 17, 2005, an obvious low point displacement dividing line was formed in China (upper in Figure 7), in which the low point time at north part moved forwards during 5 6 o'clock Beijing time (normal low point time being 12 o'clock of local time), while the low point time at south part moved backwards during 15 17 o'clock, forming about 10 hour time difference be- 
tween the two parts. On February 15, 29 days after the low point displacement event, a 6.2 earthquake $\left(41.6^{\circ} \mathrm{N}, 79.3^{\circ} \mathrm{E}\right)$ occurred in Wushi, western Xinjiang. In order to compare the spatial anomaly and low point displacement, electron data recorded by Langmuir probe on DEMETER on January 16, 17, 18 was downloaded, and 24 orbits flying across China were collected. Same data limits were used in three contour images (lower in Figure 7). Figure 7 shows that, the image of date 17 exists apparent different from that of 16 and 18, with $N_{\mathrm{e}}$ quickly increasing to form a dense contour line distribution, while the distribution scale of high values enlarging relative to the day before and after it. On 17, the maximum of $N_{\mathrm{e}}$ increases approximately with an amplitude of $40 \%$ relative to the other two days. In addition, there exists local high values at $\left(110^{\circ} \mathrm{E}, 18^{\circ} \mathrm{N}\right)$, while this high value area weakening in amplitude and moving to west on date $18 . N_{\mathrm{e}}$ at $20^{\circ} \mathrm{N} \sim 50^{\circ} \mathrm{N}$ of date 17 were higher than those of the other two days, showing smaller region with $N_{\mathrm{e}}$ lower than $11000 \mathrm{~cm}^{-3}$ (dark blue). At east $120^{\circ} \mathrm{E}, 40^{\circ} \mathrm{N} \sim 50^{\circ} \mathrm{N}$, there exists another high value region, while low values is evenly distributed at high latitude in other two days. Summarizing these three

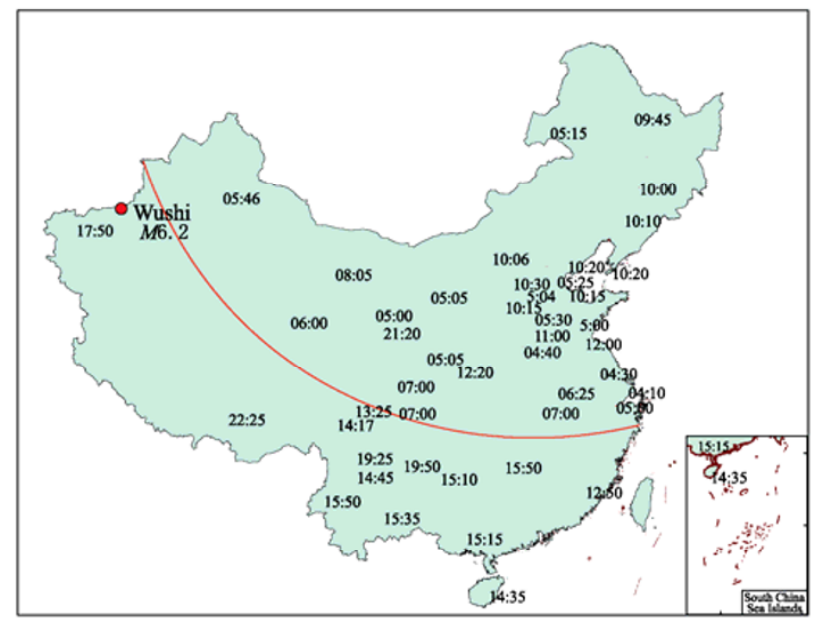

(a)

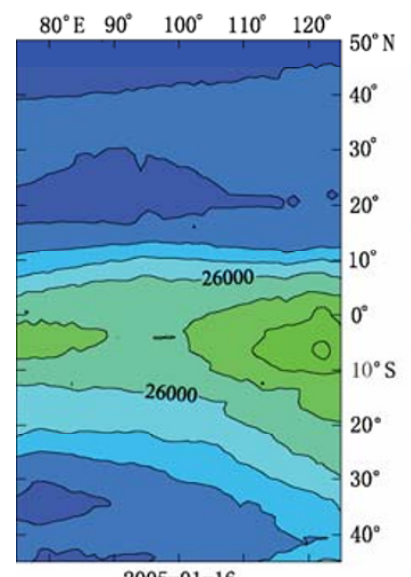

2005-01-16

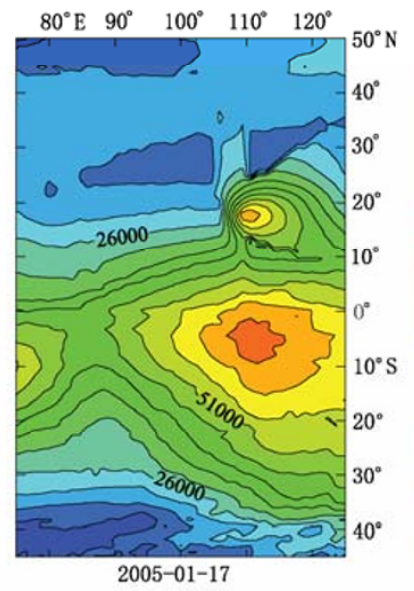

(b)

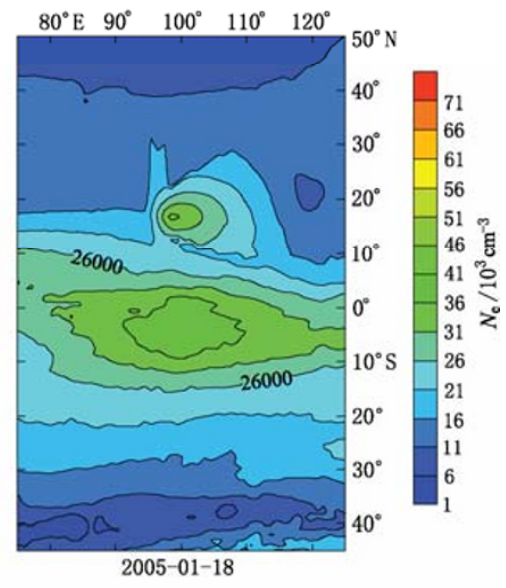

2005-01-18

Figure 7 Low point displacement image on January 17, 2005 and spatial $N_{\mathrm{e}}$ variation images during $16-18\left(75^{\circ} \mathrm{E} \sim 120^{\circ} \mathrm{E}, 45^{\circ} \mathrm{S} \sim 50^{\circ} \mathrm{N}\right)$ 
images, on January 17, 2005, the phenomenon of $N_{\mathrm{e}}$ increase occurred indeed at the ionospheric highness $(710 \mathrm{~km})$, which illustrated that disturbance existed assuredly in the ionosphere on the date of 17 , so spatial ionospheric variation was well corresponded with the phenomenon of low point displacement.

On March 5, 2005, at the southwest of China, a low point displacement event formed (upper Figure 8), intraday low point of all stations located at southwestern China moved forwards 7, 8 hours, being $6 \sim 7$ o'clock at the early morning. The anomalous dividing line was obvious. After this event, a M5 earthquake took place in Xinjiang, China on March 24, while at the extended line of the dividing line, a M8.5 earthquake occurred in Indonesia, south of China, on March 28. Fore-and-aft four days $N_{\mathrm{e}}$ data above China was downloaded around this event, from March 3 to 6 (lower in Figure 8). The results show that, on March 3, there occurred peak values at the two sides of equator of $10^{\circ} \mathrm{S} \sim 20^{\circ} \mathrm{N}$, with the amplitude of about $22000 \mathrm{~cm}^{-3}$; since March 4 , the scale of peak values enlarged, with the maximum amplitude reaching $39000 \mathrm{~cm}^{-3}$, and $N_{\mathrm{e}}$ at north sphere increase, but less apparently than that of equator; On March 5, the peak values increased largely, with the maximum amplitude reaching $45000 \mathrm{~cm}^{-3}, 2$ times of that on March 3, where the scale enlarged continuously; on March 6, the whole peak values were scattered, being south and north sphere and around equator respectively, with the amplitude recovering to the level of that on March 3, obviously different from those on March 4 and 5.

The location of dividing lines in these two low point displacement events was different and the stations showing anomalies also were different, but the spatial $N_{\mathrm{e}}$ images were with well similarity, that is spatial $N_{\mathrm{e}}$ variation image exhibited notable increase at equatorial peak value segment, which reflects that there exists evident relationship between spatial electromagnetic variation and Earth geomagnetic field variation.

By viewing the spatial variation images during these two low point displacement intervals, $N_{\mathrm{e}}$ showed the feature of integral increase, especially at the equator region. The $N_{\mathrm{e}}$ in north China relatively rose, but dividing area could not be found responding to the low point dividing part, so spatial anomalies were with much larger scale. It indicates that the increase of ionospheric electron density may cause the aberration of surface geomagnetic observing data, exciting stronger electromagnetic activity of deep-seated media at more active area, consequently forming the phenomenon of low point displacement in geomagnetic vertical component. Or it is thought that low point displacement is the combination action of space and Earth electromagnetic field. Spatial electromagnetic field variation produces induced magnetic field at active area of underground media, leading to the aberration of daily variation in geomagnetic observation and the movement of low point time, and then forming the phenomenon of low point displacement in a large scale. Therefore, low point displacement is produced by coupling of space and the Earth, not just only the result of underground media movement.

\section{Conclusions}

By the spectrum analysis of geomagnetic $Z$ component at Changli staion in Hebei Province and comparison with spatial data and images, it is found as follows:

1) Geomagnetic energy spectrum during geomagnetic storms is generally higher than those during normal time, the amplitude rising to about an order of magnitude, especially at short period part, which reflects the enhancement effect of magnetic energy during magnetic disturbances; 


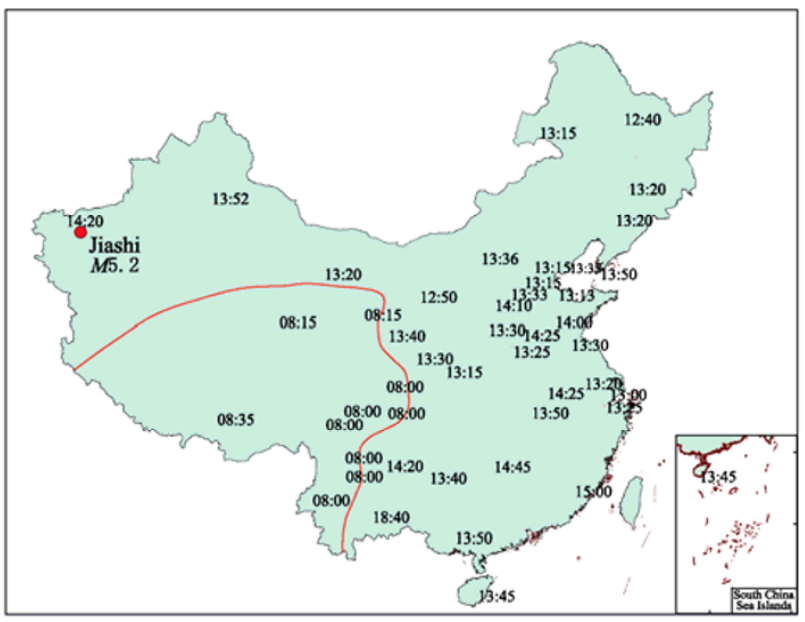

(a)
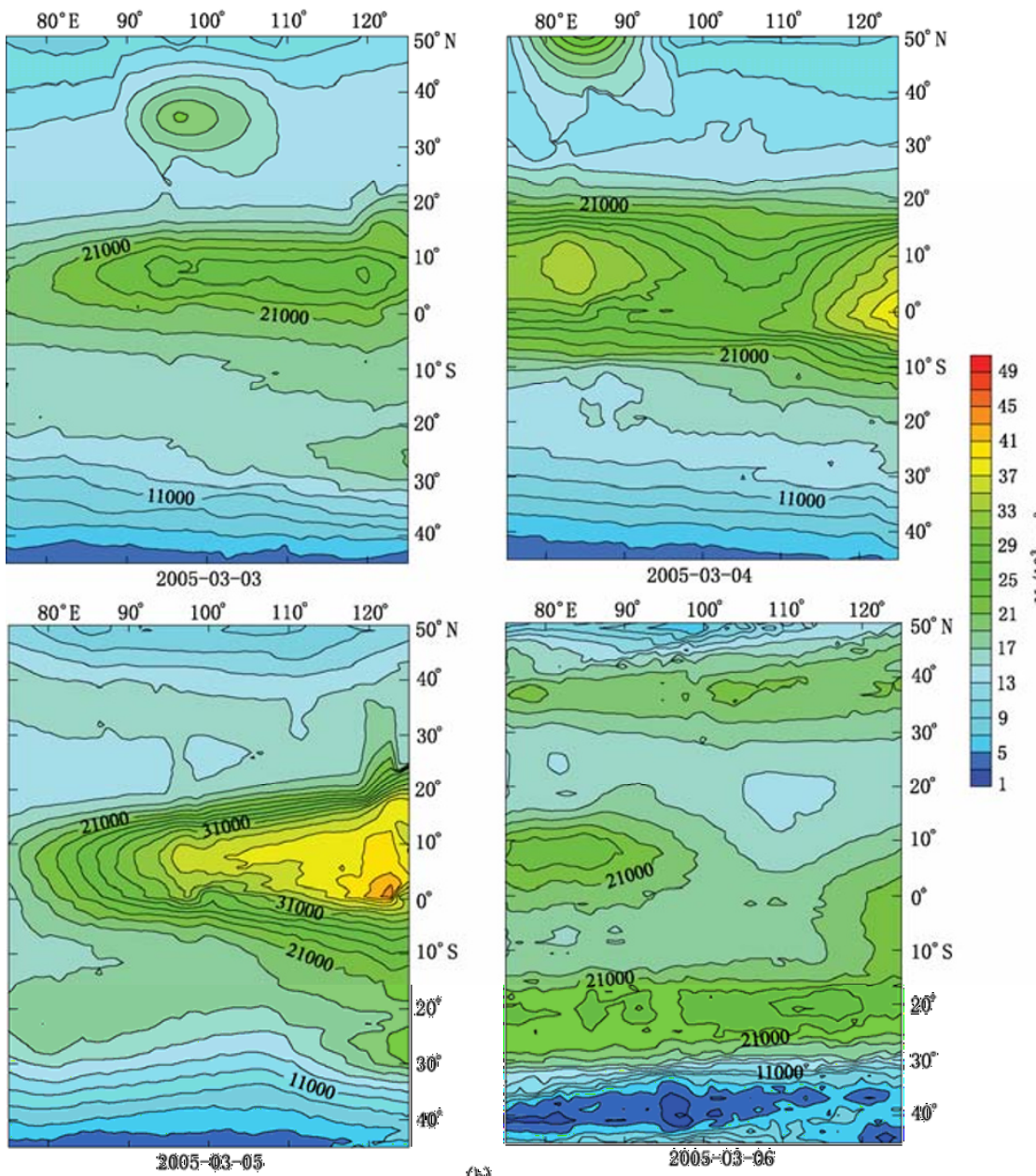

(b)

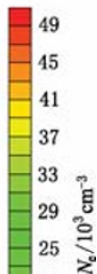

Figure 8 Low point displacement image on March 5, 2005 and spatial $N_{\mathrm{e}}$ variation images during $3 \sim 6\left(75^{\circ} \mathrm{E} \sim 120^{\circ} \mathrm{E}, 45^{\circ} \mathrm{S} \sim 50^{\circ} \mathrm{N}\right)$ 
2) Spectrums at different frequency during low point displacement are smaller than those during normal time, especially at long period part, the amplitude reducing to about half an order of magnitude;

3) Based on the distribution of spectrums, we can clearly distinguish the geomagnetic storm, normal time and low point displacement anomaly, while spectrum analysis also provides an effective tool for discriminating artificial disturbances;

4) By comparison of multi-days FFT accumulation during low point displacement and normal time, it is found that when low point displacement occurs, the spectrums at period of 8.5 and 13.7 hour increase, which illustrates that the source causing low point displacement may come from deep mantle media;

4) Compared with spatial electron density, responding to the time of low point displacement, space ionosphere shows the phenomenon of electron density increase with larger scale at equator and its two sides on same day. But, there is no spatial corresponding between the distribution of high values and low point displacement dividing line, and there is no apparent relationship to the movement forwards or backwards of geomagnetic low point time. Summing up, it is thought that, the formation of geomagnetic low point displacement may be related to the electromagnetic coupling effect of space and Earth ionosphere-lithosphere, in which large-scaled increase of ionospheric electromagnetic signals may cause aberration of observed geomagnetic signals, forming the phenomenon of geomagnetic low point displacement. The mechanism of space-earth coupling needs further study in future.

Acknowledgement We are appreciated for the DEMETER Data Center of France to provide the space observing data.

\section{References}

DING Jian-hai and HUANG Xue-xiang. 1988. Phenomena of geomagnetic low point displacement and its relation to earthquakes [J]. Acta Seismologica Sinica, 10(4): 552-561 (in Chinese).

DING Jian-hai, LIU Jie, YU Su-rong. 2004. Geomagnetic daily variation anomalies and relation to earthquakes [J]. Acta Seismologica Sinica, 26(Suppl.): 79-87 (in Chinese).

DING Jian-hai, SUO Yu-cheng, YU Su-rong. 2005. Phenomena of geomagnetic and ionospheric anomalies and their relation to earthquakes [J]. Chin J Space Sci, 25(6): 536-542 (in Chinese).

DING Jian-hai, YU Su-rong, SUO Yu-cheng. 2006. The application of varying geomagntic field data in short-term strong earthquake prediction [M]//Department of Monitoring and Prediction, China Earthquake Administration. Study on Short-term Prediction Method by GPS, Satellite Remote Sensing and Varying Geomagnetic Field Data. Beijing: Seismological Press: 1-179 (in Chinese).

GUO Zeng-jian, QIN Bao-Yan, LI Hai-hua, et al. 1977. Geomagnetic Storm, weather rhythm and time of earthquake occurrence. Earthquake Frontier, (3): 26-29.

HUANG Xue-xiang and YU Su-rong. 2000. The characteristics of geomagnetic low-point displacement anomaly and their relation to seismicity [J]. Earthquake, 20(4): 39-44 (in Chinese).

Lebreton J P, Stverak S, Travnivek P, et al. 2006. The ISL Langmuir probe experiment procession onboard DEMETER: Scientific objectives, description and first results [J]. Planetary and Space Science, 54(5): 472-486.

LI Ming-guang and LIANG Xiu-lan. 1989. Study on seasonal variation for the low point time of geomagnetic $Z$ component [J]. Earthquake Research in Sichuan, 4: 50-59 (in Chinese)

LI Qi, YANG Dong-mei, ZHANG Su-qin, et al. 2005. Typical example and comparison between digital data and simulated data of geomagnetic transfer function [J]. Earthquake, 25(3): 85-90 (in Chinese).

LU Yuan-zhong, DENG Zhi-hui, LI Sheng-le. 2000. Earthquake Analysis Forecast System on GIS [M]. Chengdu: Chengdu Map Press: 1-232 (in Chinese).

Parrot M, Berthelier J J, Lebreton J P, et al. 2006. Examples of unusual ionospheric observations made by the DEMETER satellite over seismic regions [J]. Physics and Chemistry of the Earth, 31: 486-495.

Pulinets S A, Boyarchuk K A, Hegai V V, et al. 2000. Quasielectrostatic model of atmosphere-thermosphere-ionosphere coupling [J]. Adv Space Res, 26(8): $1209-1218$.

SHI Yong-jun, SUN Yan-ping, ZHU Yan, et al. 2002. Study on varying characteristics of loading/unloading response ratio observed at Kashi, Xinjiang, station during Jiashi strong earthquake swarm [J]. Inland Earthquake, 16(1): 84-88 (in Chinese).

WU Xiao-ping, XIN Hua, ZHANG Yong-jiu. 2004. Predicting the time of an earthquake using the data of geomagnetic low point move- 
ment and storm [J]. Earthquake Research in Sichuan, (2): 22-26 (in Chinese).

WU Xiao-ping. 2003. Predicting the occurrence times of earthquake using movement of geomagnetism low point [J]. Earthquake Research in Sichuan, (1): 33-36 (in Chinese).

XIE Yong-ming and QIAO Zi-yun. 2003. The application of the geomagnetic convergence method in the earthquake prediction [J]. Earthquake Research in Shanxi, (1): 27-29 (in Chinese).

ZHAO Jie, ZHU Zhen-jia, ZHANG Cai-yan, et al. 2005. Discussion on the abnormity displacement and disturbance factors of the low points of geomagnetic component in Jiayuguan [J]. Seismological and Geomagnetic Observation and Research, 26(6): 42-45 (in Chinese). 